Bull. Fac.Agric., Cairo Univ. 64:220-227 (2013)

\title{
A STUDY OF THE ENTERPRISE BUDGET OF OLIVE CROP AND SOCIO-ECONOMIC CHARACTERISTICS OF THE OLIVE FARMERS IN KARAK GOVERNORATE, JORDAN
}

(Received: 26. 4. 2013)

\author{
By \\ M. A. Bdour and A. N. Al-Shadiadeh* \\ Department of Plant Production, Faculty of Agriculture, Mutah University, Karak \\ *Department of Plant Production \& Protection, Faculty of Agricultural Technology \\ Al Balqa' Applied University, Al-Salt, Jordan
}

\begin{abstract}
The aim of this study was to assess the competitive olive crop, through identification the economic and social characteristics of the farmers, and the study of the enterprise budget for the olive crop in Karak Governorate. Also to identify the strengths and weaknesses on one hand, and the opportunities and Threats facing the olive sector on the other hand, a questionnaire used as a tool to collect the data through a personal interview, then analyzed to extract the economic, social characteristics, and enterprise budget by using the program (SPSS). In addition, a matrix of four variables (SWOT)was used to examine the strengths and weaknesses in the olive sector, as well as to identify opportunities and threats facing this sector.

The results showed that $80 \%$ of olive farmers are working in olive cultivation as a part time, $85 \%$ of the employment in this sector is a family labor, and about $63 \%$ of the farmers needs supplementary irrigation.

Study the enterprise budget of olive crop showed that the rate of olive oil production per dunam reached $47 \mathrm{~kg}$, the average price was $3.5 \mathrm{JD} / \mathrm{kg}$, and the average production of $1 \mathrm{~kg}$ of olive oil reached 3.48 dinars, while the Break-even Yield $46.8 \mathrm{~kg} /$ dunam , the Gross margin 61.5 JD / dunam and Net profit $0.8 \mathrm{JD}$. The results showed that the total costs amounted to $163.3 \mathrm{JD} /$ dunam, $103 \mathrm{JD}$ of which are variable costs, accounted for supplementary irrigation water costs $58 \%$ of them.

The study used SWOT matrix also to identify the strengths and weaknesses of the olive sector in Jordan as well as to identify the opportunities and threats facing the sector.

Therefore, the study suggests develop a strategic plan for the development of this sector, and activating the role of agricultural extension and development of regulatory legislation to dis- allow the cultivation of olives in dry areas and to develop water harvesting techniques.
\end{abstract}

Key words: competitive crop, economic and social characteristics, enterprise budget, olive.

$$
\begin{aligned}
& \text { دراسة ميزانية النشاط المز رعي والخصائص الاجتماعية والاقتصادية لمزارعي الزيتون في محافظة الكرك/الأردن }
\end{aligned}
$$

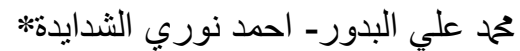

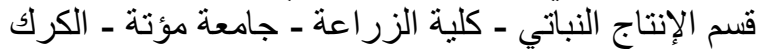

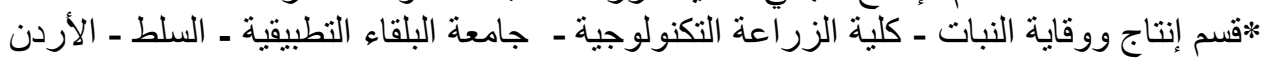

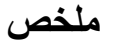

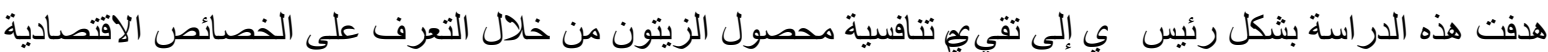

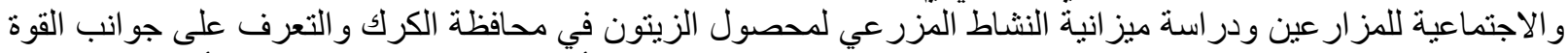

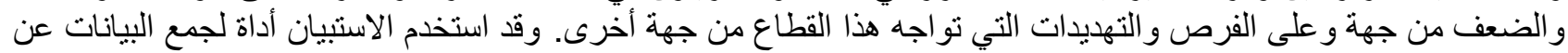

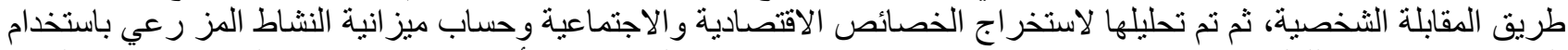

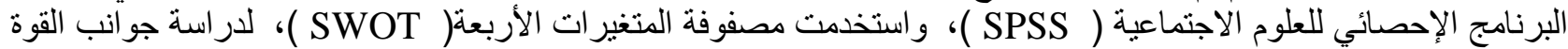

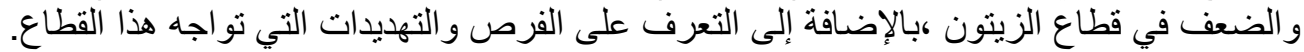




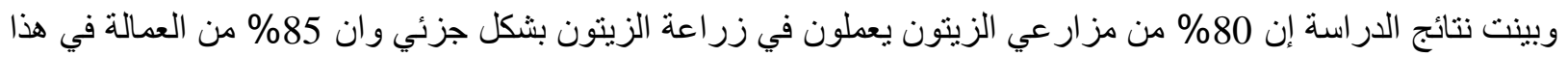

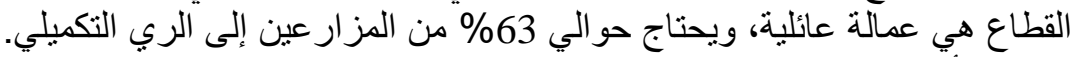

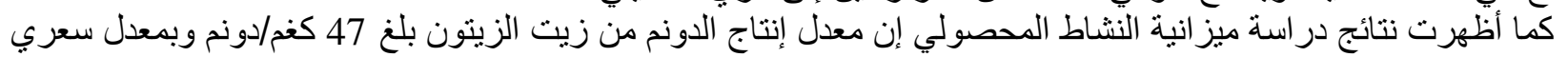

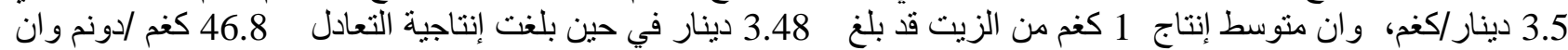

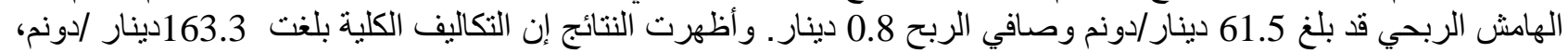

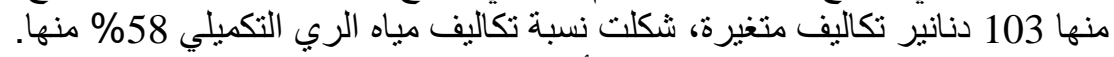

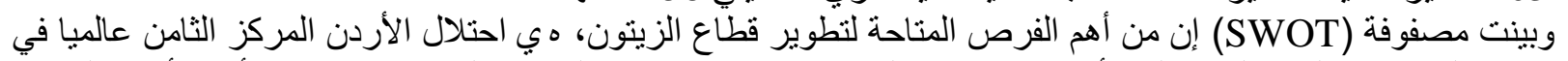

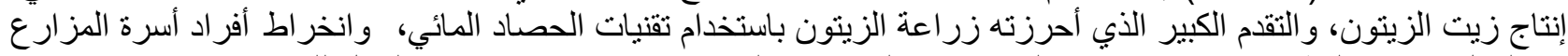

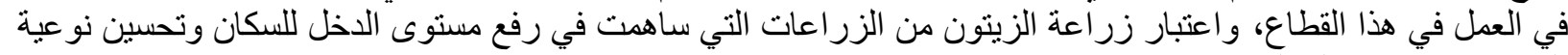
الحياة في محافظة الكرلك. ولذلك تقترح الدراسة وضع خطة الكة استر اتيجية لتطوير هذا القطاع، وتفعيل دور الإرشاد الزراعي ووضع تشتريعات ناظمة

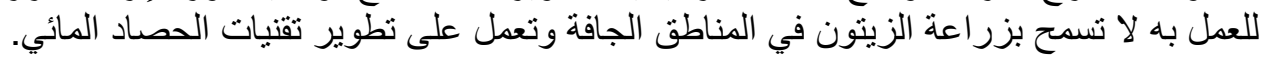

زيت الزيتون ويستخدم (151) طن لصناعة مخلات الزيتون

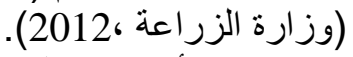
يعتبر الأردن من المواعة الطن الأصلية لزر اعة الزئن الزيتون في

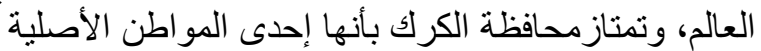

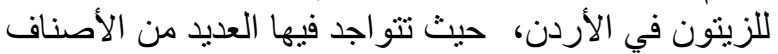

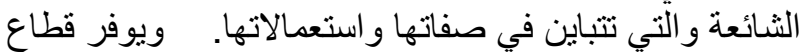

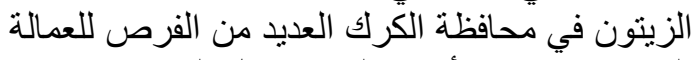

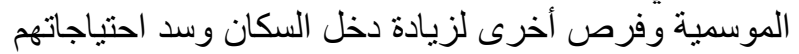

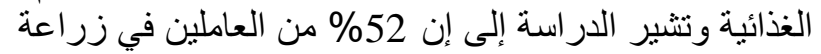

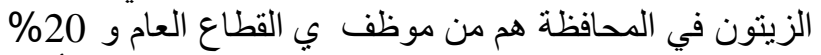

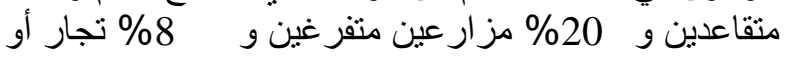
يمارسون مهن مختلفة.

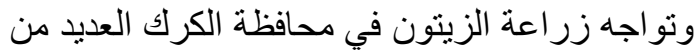

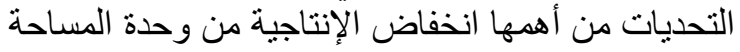

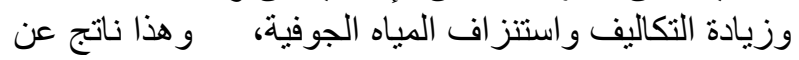

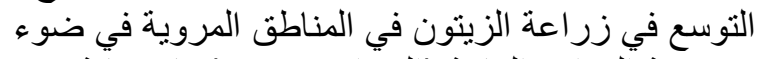

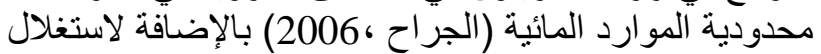

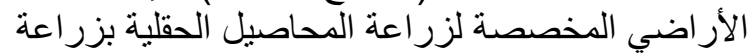

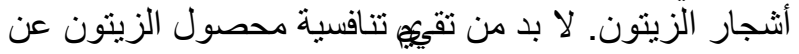

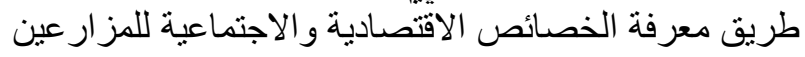

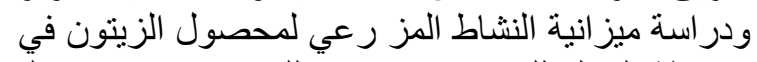

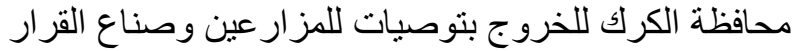

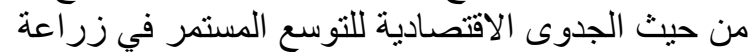
الزيتون في الأردن بشكل عام ومحافظة الكرك بشكل خئن خاص.

\section{2. المشكلة البحثية والمبررات}

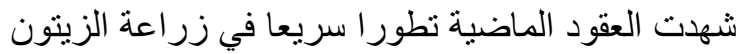

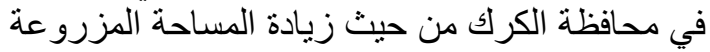

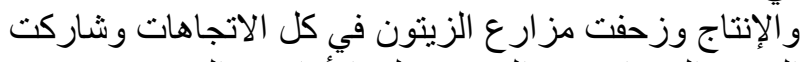

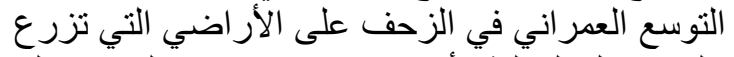

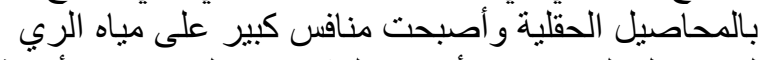

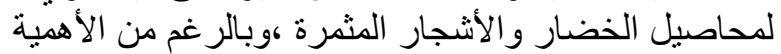

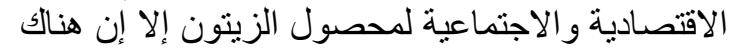
تحديات كثيرة تو اجه المزار الارعون منها تدن الإنتاجية وزيادة الإن

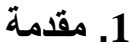

تشكل زر اعة الزيتون احد أهم ركائز التتمية الاقتصادية

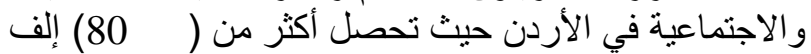

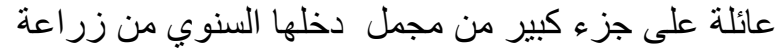

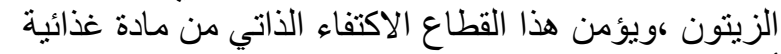

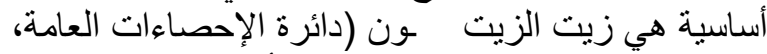

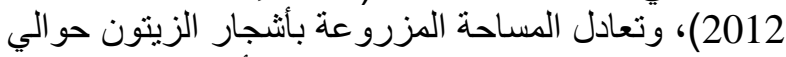

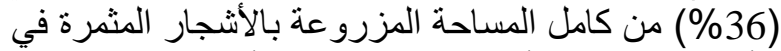
الأردن ويقدر عدد أثجار الزيتون في الأردن بحو الئي 17

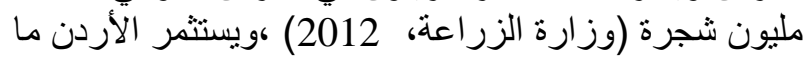

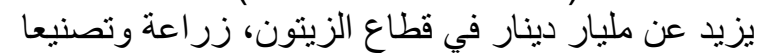

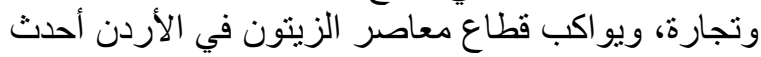

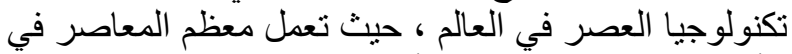

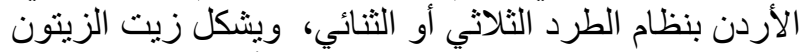

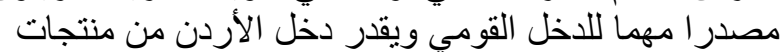



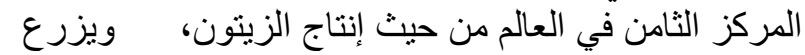

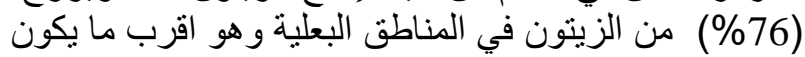

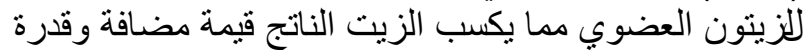

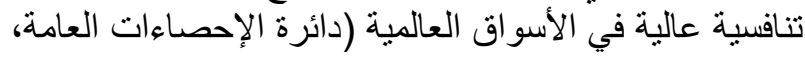

تلعب زر اعة الزيتون دور ا هاما في المنظومة الاقتصادية

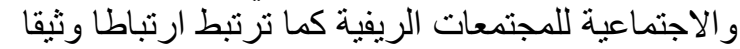

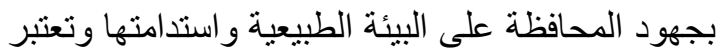

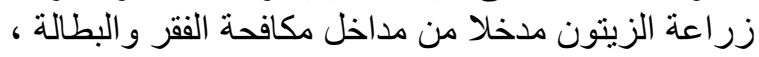

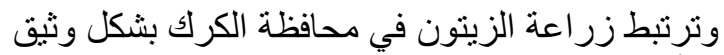

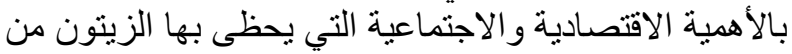

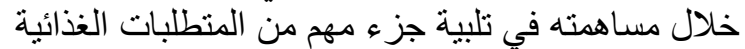

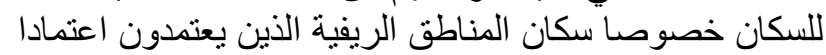

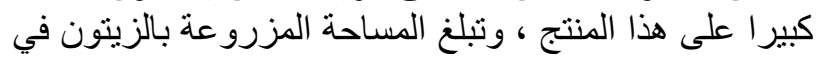

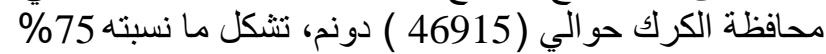

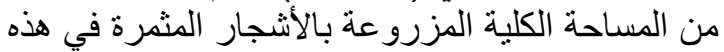

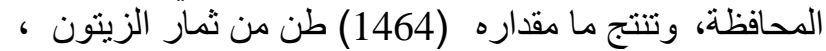

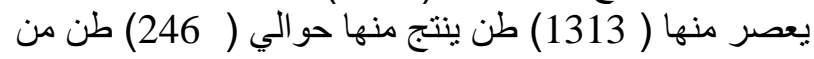


وتم تصنيف القسم الثناني إلى سبع فئات مساحية ،كما تم تصنيف المنطقة البعلية في جرش ضمن الفي خمس فئات مساحية

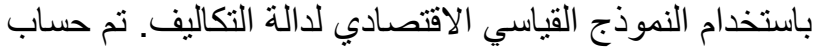

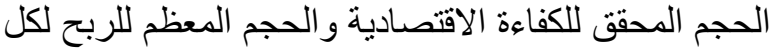

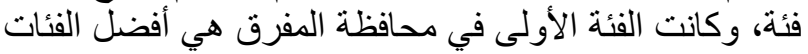

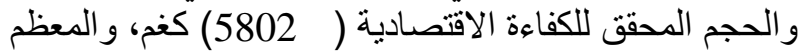

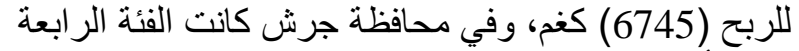

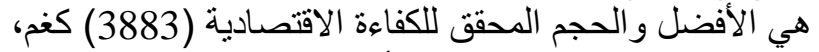

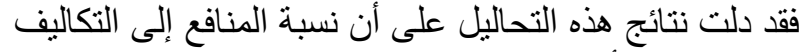

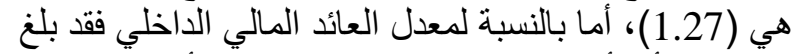

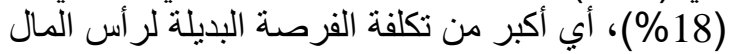

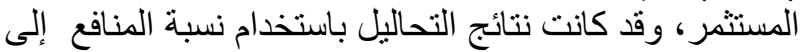

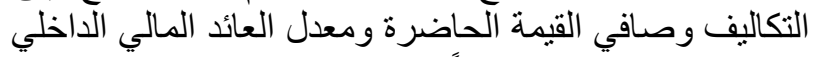

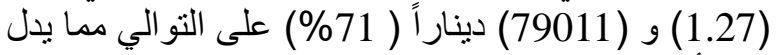
على أن للمشروع جدوى مالية .

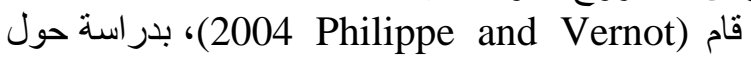
استصلاح حوض نهر الأردن تناول فيها أنظمة زر اعة أنثجار

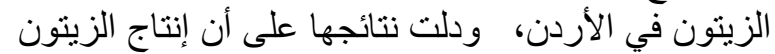

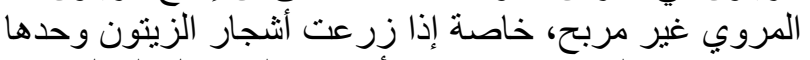

دون زر اعة الخضر او ات بين الأشجار على على سبيل المثنال. ومهما يكن من أمر فقد دلت نتائج الدر اسة الته على جدوى إلى إنتاج الزيتون في المناطق البعلية.

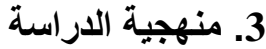

1.3. منطقة الدراسة

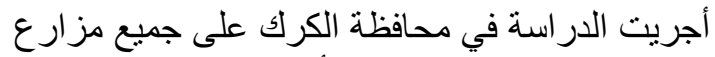

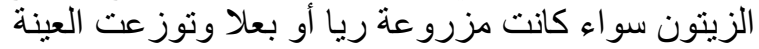

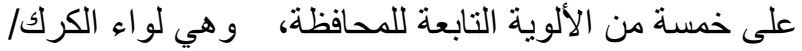

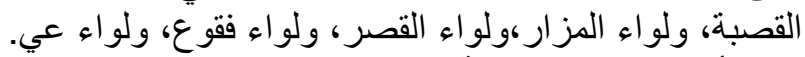

2.3. أسلوب اختيار العينة

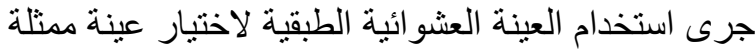

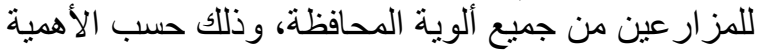

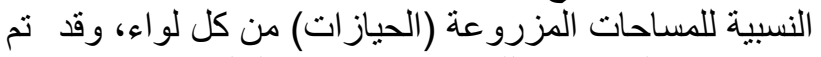
تحديد حجم العينة وفقا للقانون الإحصائي التالي:

$\mathrm{N}=\frac{(\mathrm{Z})^{2}(\mathrm{P})(1-\mathrm{P})}{\mathrm{e}^{2}}$. Stevenson (1978).....

حيث أن:

N = مجم العينة المطلوب

الدرجة المعيارية الحرجة عند مسنوى معنوية $\mathrm{Z}=\% 95$

P = $\quad$ Pتمالية تمثيل العينة للبيانات

التمالية عدم تمثيل العينة البينة

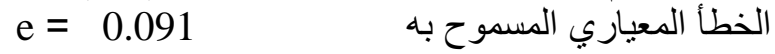
وبتطبيق هذه المعادلة وجد إن حجم العينة بلغ ( تقسيم مفردات العينة على ألوية المحافظة كما في الجدول العينة

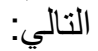

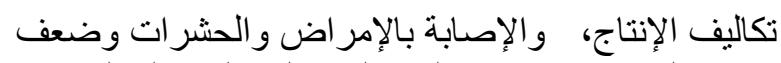

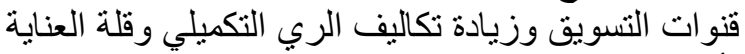

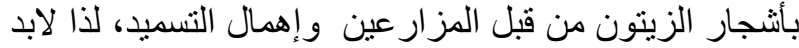

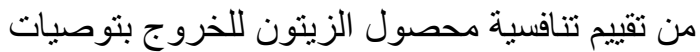

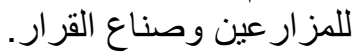

1.2. تهذف هذه الاراسة إلى الى الى

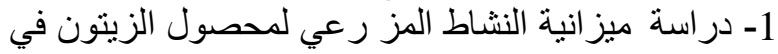

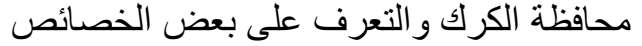
الاقتصادية و الاجتماعية لمز ارعي الزئي الزيتون.

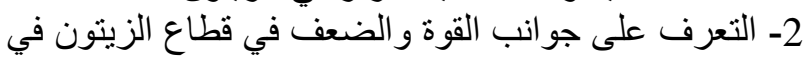

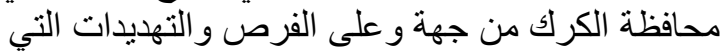
تو اجه هذا القطاع من جهة أخرى الخئ 2.2.

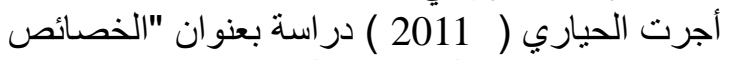

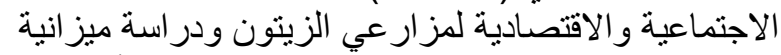

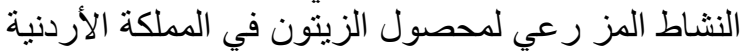

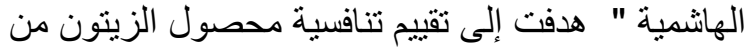
خلال التعرف على الخصائص الاقتصادية و الاجتماعية

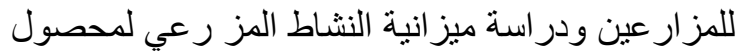

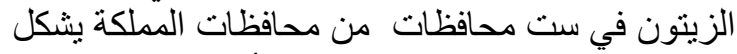

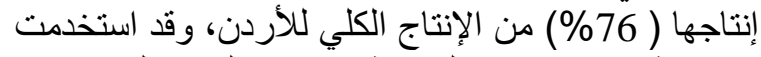

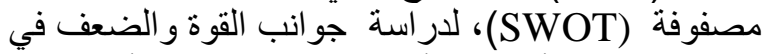

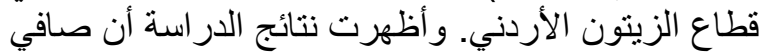

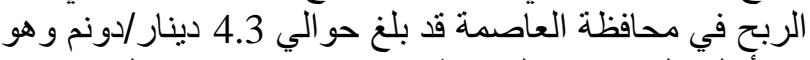
من أعلى النسب بين المحافظات، بينما كان صافي العافي الربح في

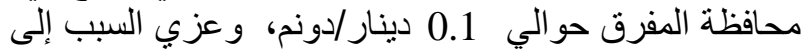

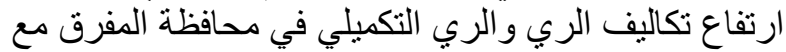
صغر حجم الحياز ات الزراعية الرية الزية

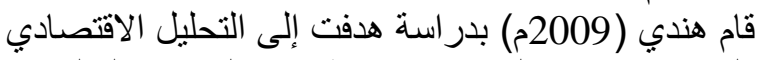

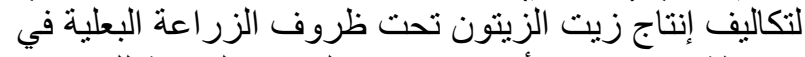

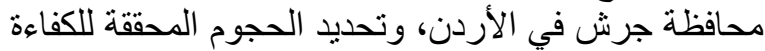

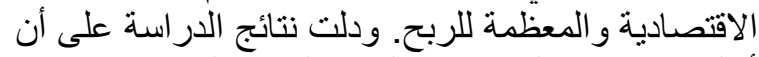

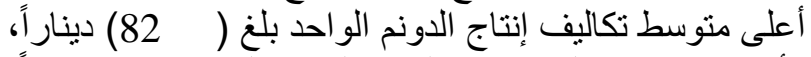

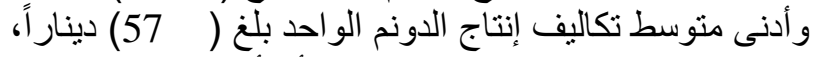

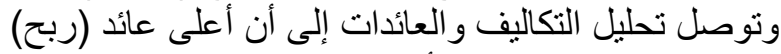

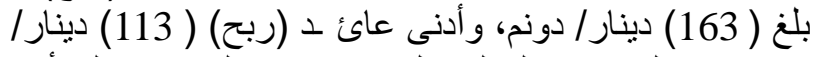

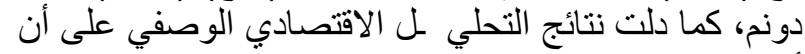

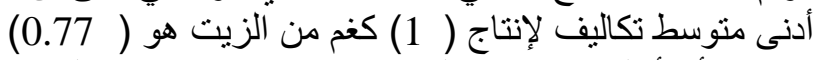

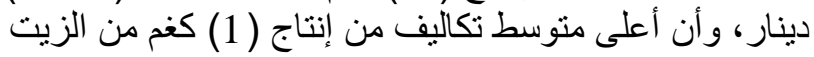

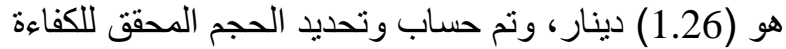

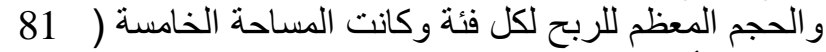
أجرى الجر اح ( 2006م) دراسة الفة حول اقتصاديات إنتاج

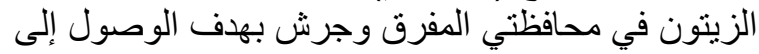

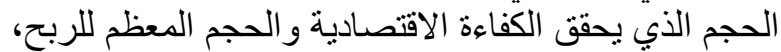

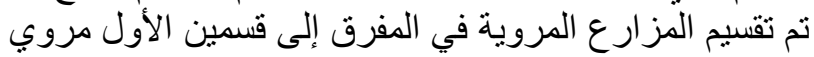

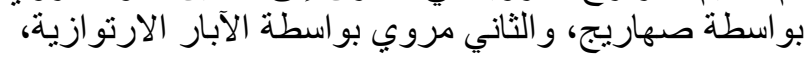


المقابلات مع المعنيين بالقط ــاع من المزارعي_ن و أصحاب

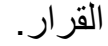

\section{4. النتائج البحثية}

1.4. الخصائص الاجتماعية والاقتصادية اليجة

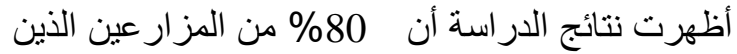

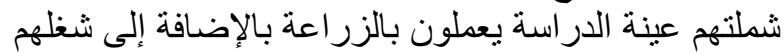

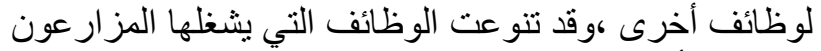

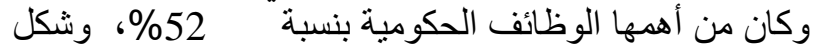

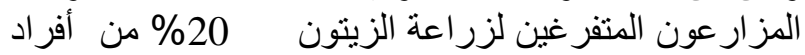

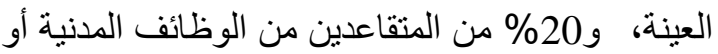

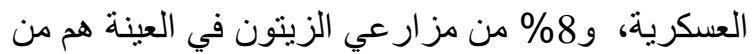

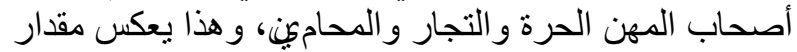
الأهية الاقتصادية والاجتماعية لشجرة الزيجة الزيتون في حياة سكا

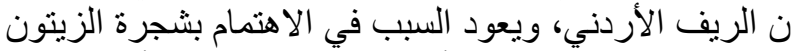

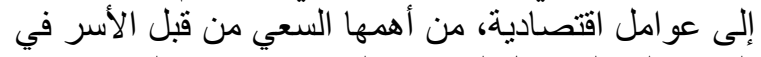

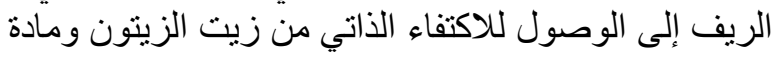
كبيس الزيتون ( مخلل الزيتون )، والتي تعتبر مادة غذائية التئية

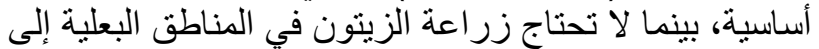

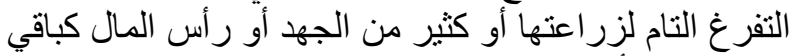

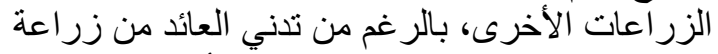

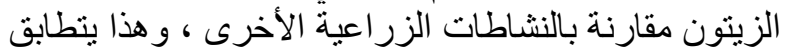

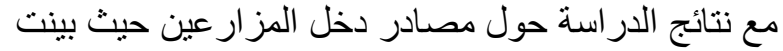

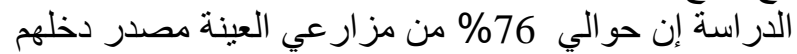
الأساسي من الوظائف الحكومية أو الرو اتب التب التقاعدية ، بينما

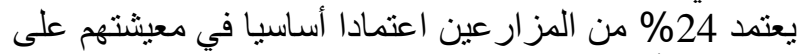

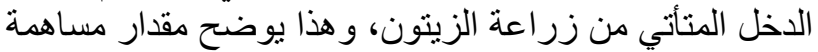

قطاع الزيتون في توفير الدخل للأسر الريفية في محافظة

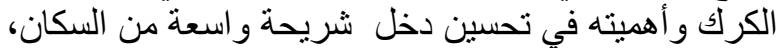

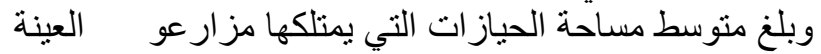
حو الي 33 دونم، حيث تر اوحت مساحة الحياز ات بين ( 20 ـ

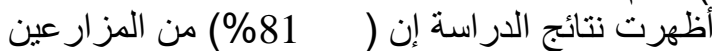

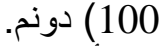

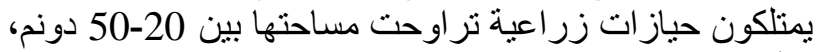

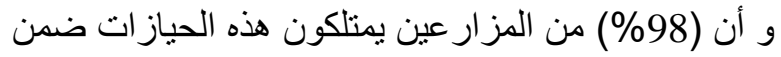

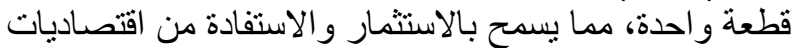

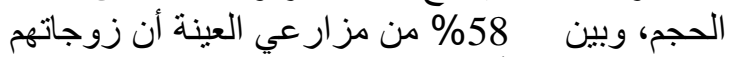

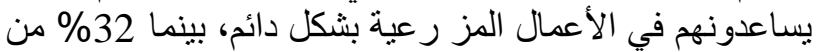

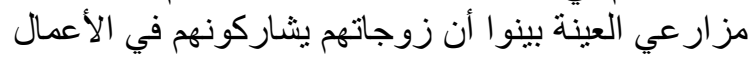

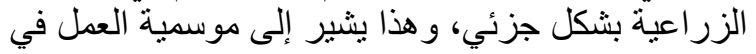

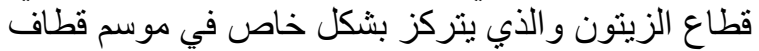

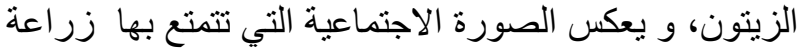

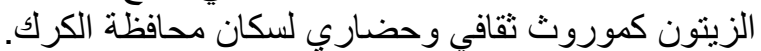
2.4. أنواع الزراعة والتئنيات المستخدمة

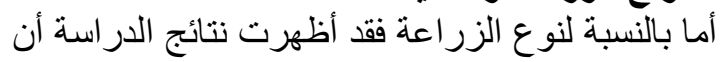

27\% من المزارعين يعتمدون على الزر الزعة البعة البعلية، بينما 63

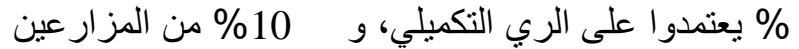
يزر عوا زر اعة مروية.
جدول ( 1): التوزيع النسبي لمفردات العينة على ألوية المحافظة وفقا لعدد المزارعين.

\begin{tabular}{|c|c|c|c|}
\hline$\%$ & عدد المزارعين & المساحة /دونم & اللواء \\
\hline 23 & 20 & 10425 & الكرك/ القصبة \\
\hline 23 & 20 & 10075 & القصر \\
\hline 18 & 17 & 8160 & فقوع \\
\hline 24 & 20 & 10868 & المزار \\
\hline 12 & 12 & 5090 & عي \\
\hline 100 & 89 & 44618 & المجموع \\
\hline
\end{tabular}

3.3. أسلوب جمع البيانات أليات

اعتمدت الدراسة على البيانات الأولية التي تم جمعهات التيات التئية

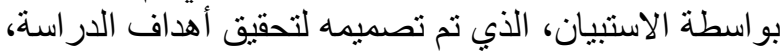

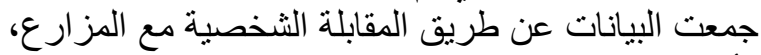

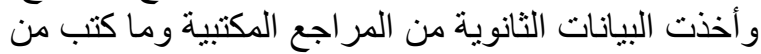

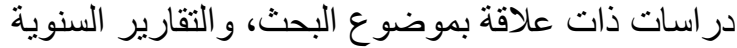

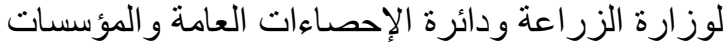
الحكومية الأخرى ذات العة العلاقة الإنة. 4.3. أسلوب تحليل البيانات العربة

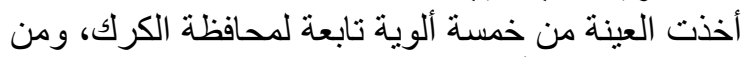

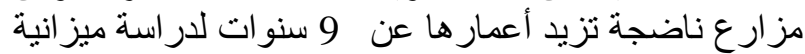

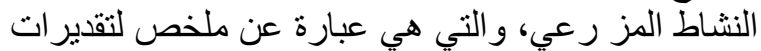

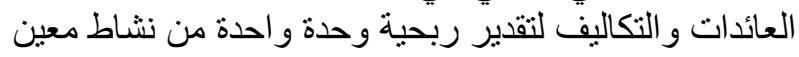
خلال فترة زمنية معينة (القاضي وبحية والريماوي، وتضمن هذا التحليل المعايير المتعلقة بأربحية ربحية الدونم الواحد،

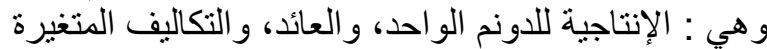

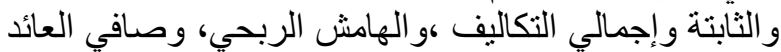

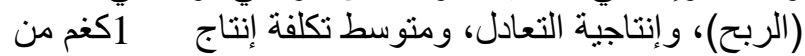

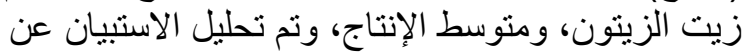

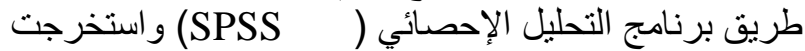

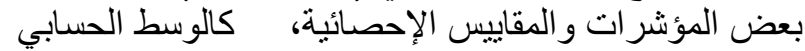

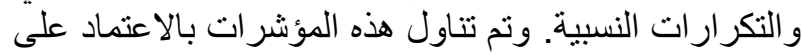

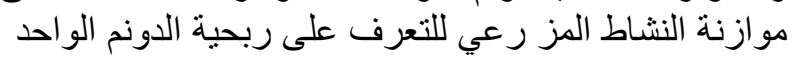
وفق المؤشر ات التالية (القاضي و الريماوي ،1996)

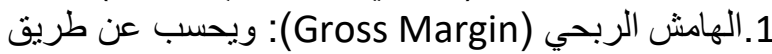
طرح التكاليف الكلية و المتغيرة من إجمالي العائدات.

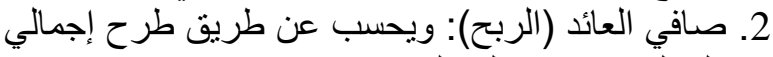
التكاليف من إجمالي العائدات.

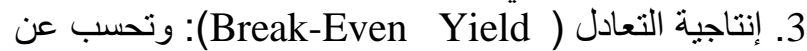

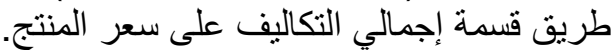

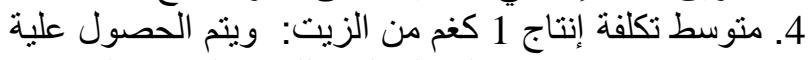

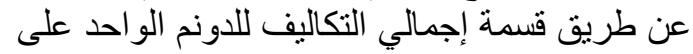

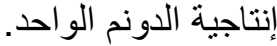

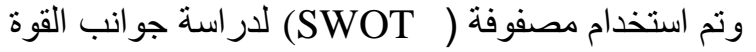
و الضعف في قطاع الزينون في محافظة الكرك بالإضافة إلى الى الى

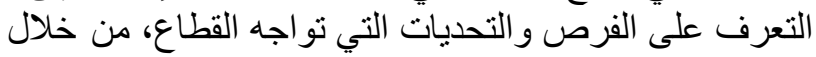




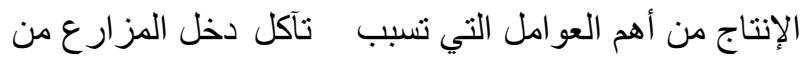

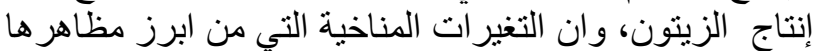

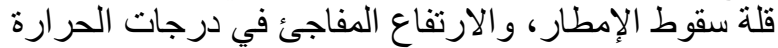

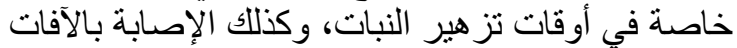

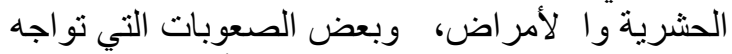

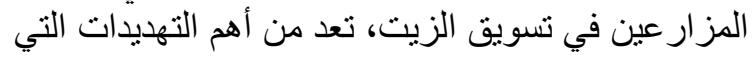

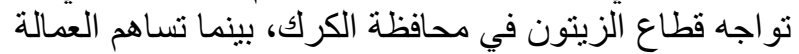

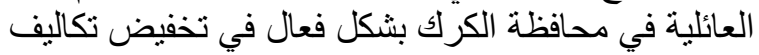

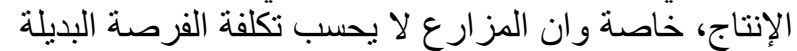

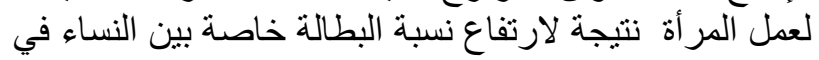

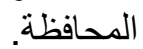

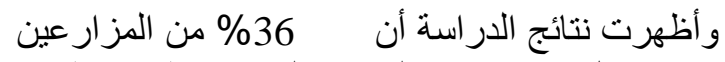

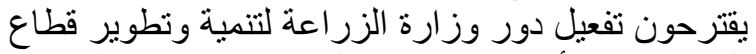

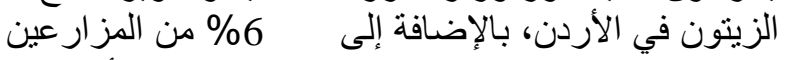

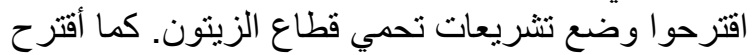

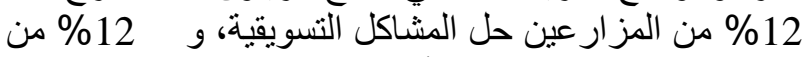

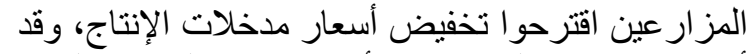
أقترح 8\% من المزار عين تأسيس جمعية لمنتجي الزيتون الزيتون

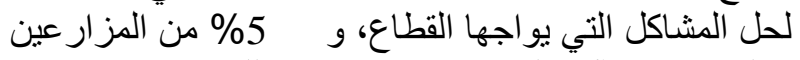

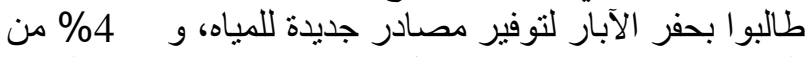

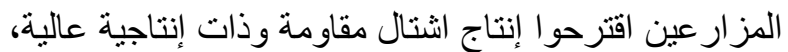

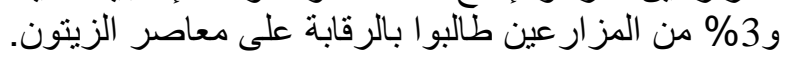

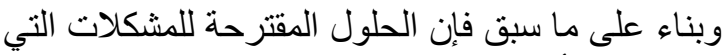

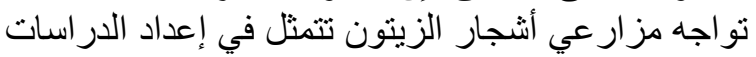

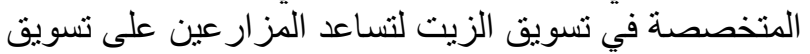

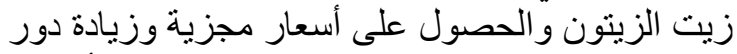

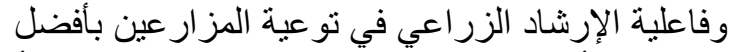

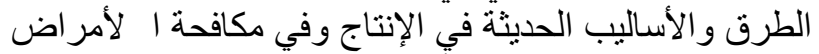

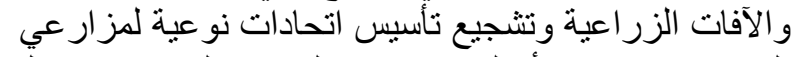

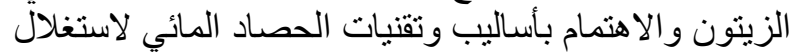
مياه الأمطار في ري أنثجار الزئن الزيتون. 4.4. دراسة ميزانية نشاط إنتاج زيت الزيتئون الزيتون

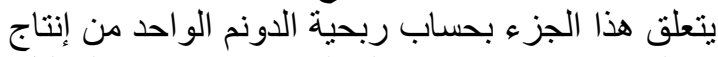
زيت الزيتون في محافظات الكرك، ويتضدمن التهن هذا التحليل

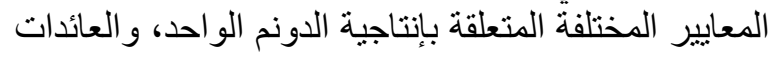

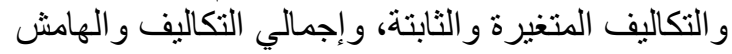

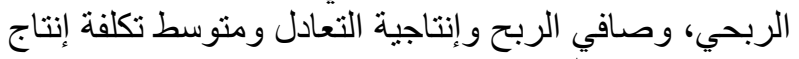

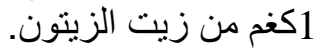

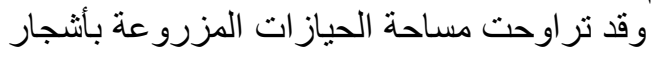

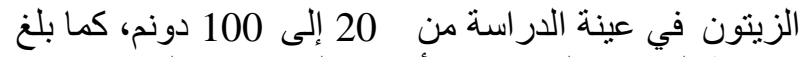

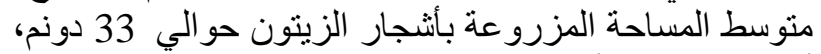

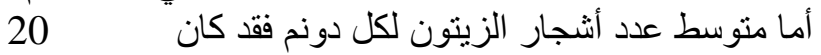

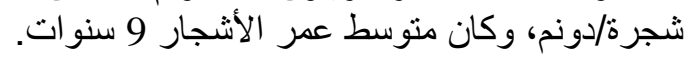

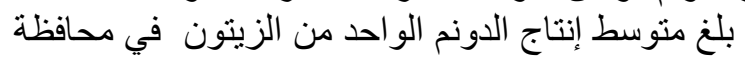

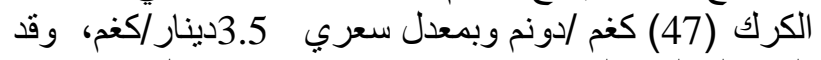

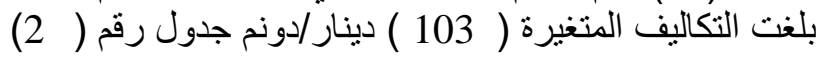
وكان ارتفاع التكاليف المتغيرة بسبب استخدام الري التكميلي

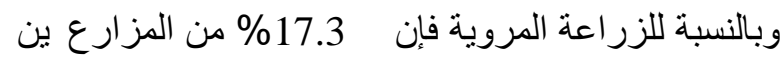

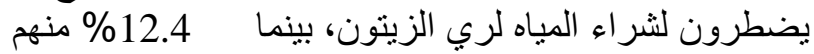

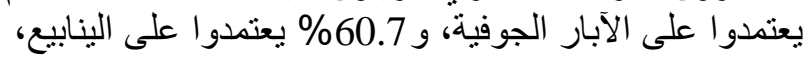

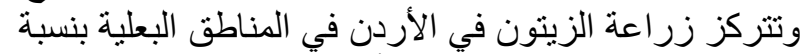

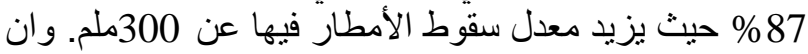

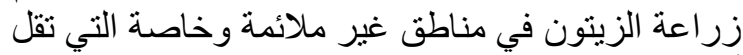

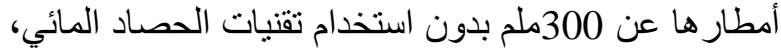

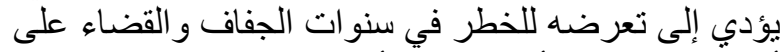

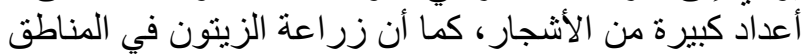

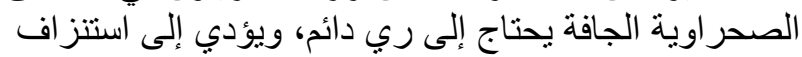

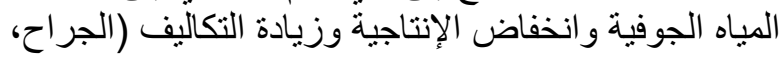

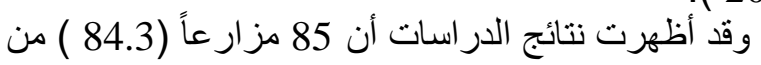
( 2006

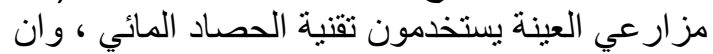

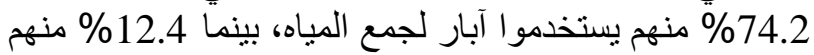

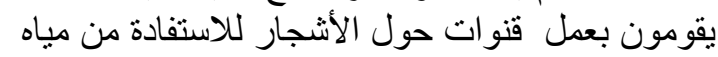

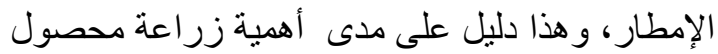

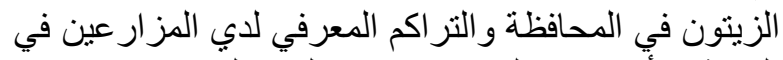

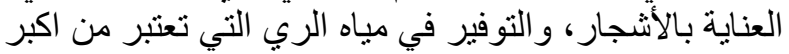

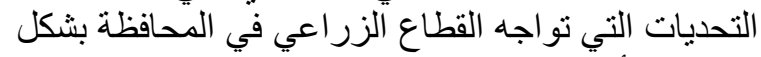

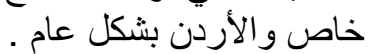

3.4. المشاكل والصعوبات التي تواجه مزارعي الزيتون

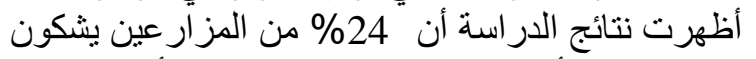

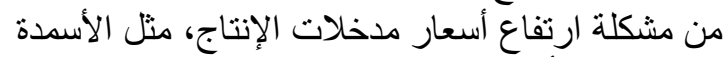

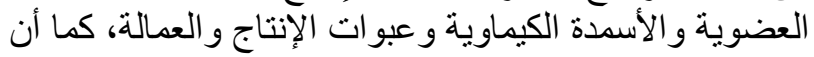

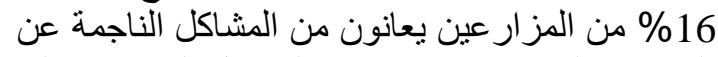

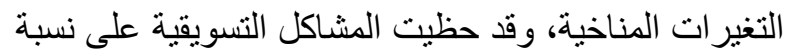

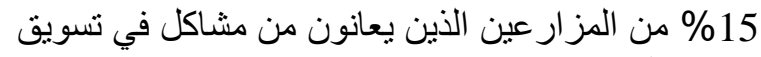

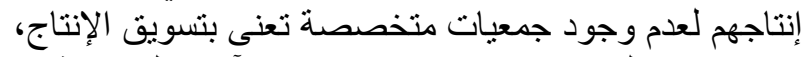

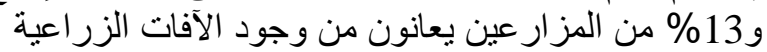
المختلفة

وقد أوضح 9 \% من المزارعين رغبتهم بوجود دور

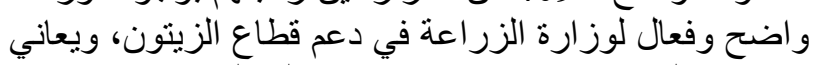

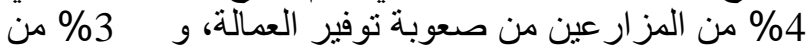

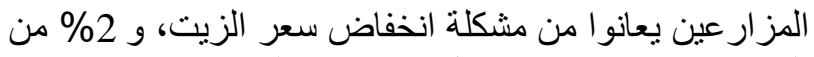

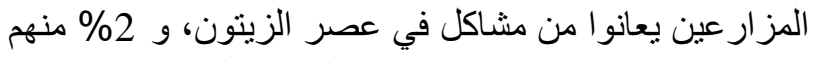

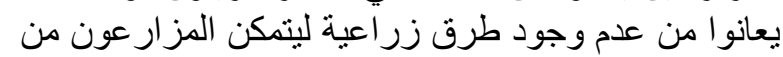

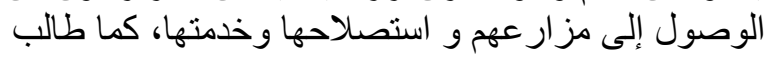

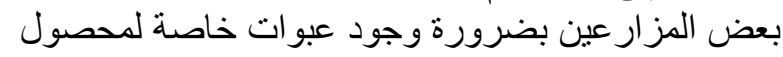

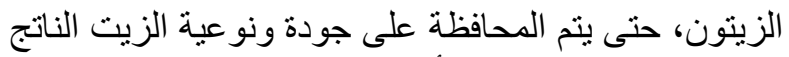

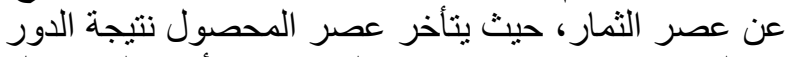

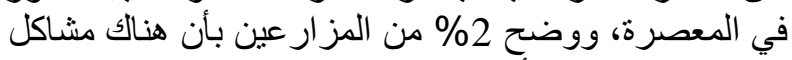

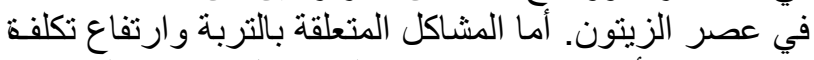

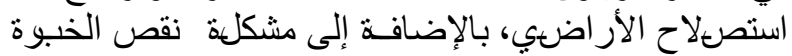

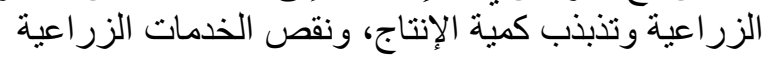

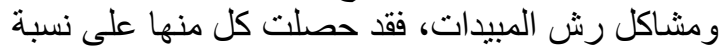
\% \% وتشير النتائج السابقة إلى إن ارتفاع أسعار مدخلات 
وتمثل إنتاجية التعادل الحد الأدنى لإنتاجية وحدة النشاط (دونم

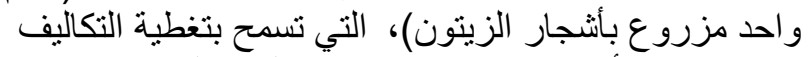

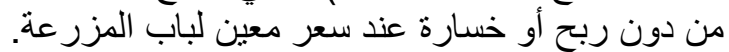

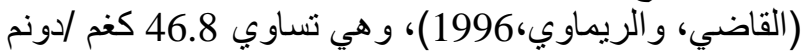

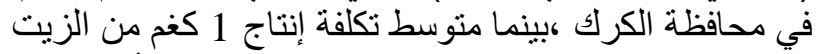

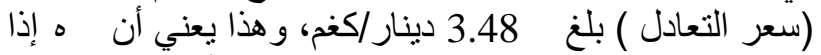

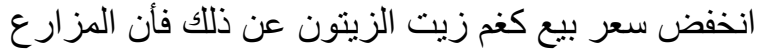

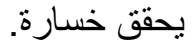
مصفوفة المتغير ات الأربعة ( SWOT) لقطاع الزيتون في

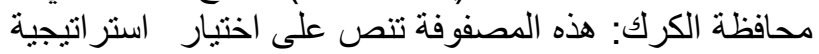

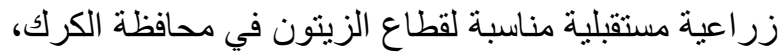

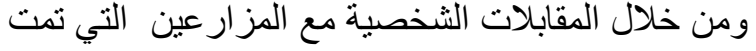

لري أثجار الزيتون حيث بلغت تكلفة أثمان المياه ما نسبته

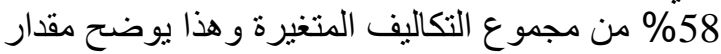

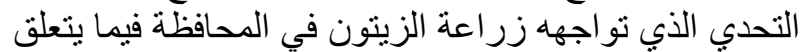

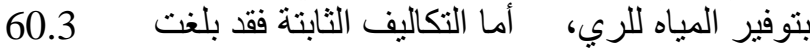

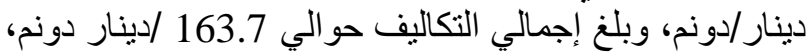

ومن الجدول ( 2) يتبين إن مؤشر التئ الربحية لإنتاج زيت

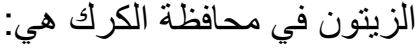

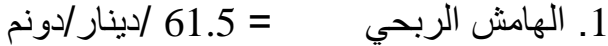
2. 3. إنتاجية التعادل

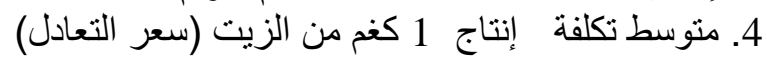
3.48=

جدول (2): ميزانية النشاط لقياس ربحية إنتاج دونم واحد من الزيتون في محافظة الكرك.

\begin{tabular}{|c|c|c|c|c|}
\hline القيمة ( دينار) & السعر ( دينار) & الكمية & الوحدة & البنود \\
\hline 164.5 & 3.5 & 47 & كفم & العائدات الإنتاج من الزيت \\
\hline 103 & & & & التكاليف المتغيرة \\
\hline 5 & & & & حراثة \\
\hline--- & & & & آمونيا \\
\hline 1.8 & 21 & 0.09 & طن & سماد عضوي \\
\hline 1.6 & 0.4 & 4 & كفم & يوريا \\
\hline 1.35 & 0.5 & 2.7 & كفم & أسمدة مركبة وعناصر نادرة \\
\hline 0.7 & 2 & 0.35 & لتر & مبيدات أعشاب \\
\hline 2.4 & 9.5 & 0.25 & لتر & مبيدات حشرية \\
\hline 1.09 & & & & عمال للوقاية \\
\hline 58 & 1 & 58 & $3 p$ & مياه \\
\hline 1 & 0.5 & 2 & عدد & عبوات حقلية \\
\hline 9 & 0.05 & 180 & كفم & القطف \\
\hline 1 & & & & نقل للمعصرة \\
\hline 14 & 0.35 & 40 & دينار & تكاليف عصر \\
\hline 2 & 1 & 2 & عبوة & عبوات للزيت \\
\hline 3 & & & & محروقات \\
\hline 1 & & & & الفائدة /\%7 \\
\hline 60.7 & & & & 3- التكاليف الثابتة \\
\hline 10 & & & & تكاليف التأسيس \\
\hline 5.7 & & & & اهتلاك المباني \\
\hline 5 & & & & اهتلاك شبكات الري \\
\hline 7 & & & & اهتلاك الآلات \\
\hline 1 & & & & اهتلاك البرك \\
\hline 10 & & & & إيجار الأرض \\
\hline 2 & & & & اهتلاك الأسوار والأسلاك \\
\hline 3 & & & & عمل عائلي \\
\hline 5 & & & & صيانة \\
\hline 7 & & & & عمال دائمةة \\
\hline 5 & & & & فـ/ على الأصول الرأسمالية \\
\hline 163.7 & & & & 4- إجمالي التكاليف \\
\hline 61.5 & & & & الهامش الربحي \\
\hline 0.8 & & & & صافي الربح \\
\hline 46.8 & & & & إنتاجية التعادل \\
\hline 3.48 & & & دينار & متوسط تكلفة إنتاج 1كفم من الزيت \\
\hline
\end{tabular}




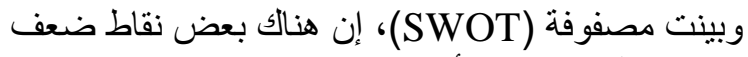

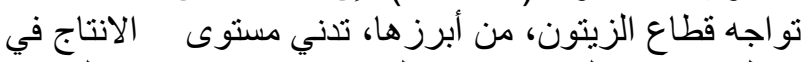

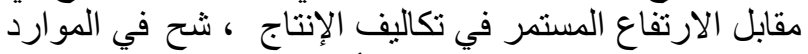

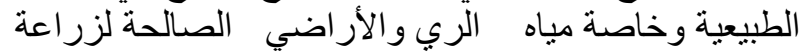

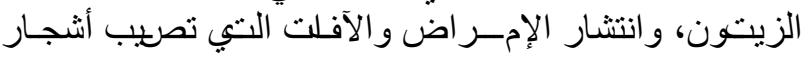

بو اسطة الاستبيان أظهرت هذه المصفوفة ما يلي: نقاط القوة

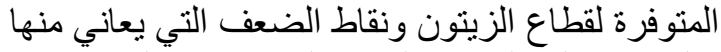

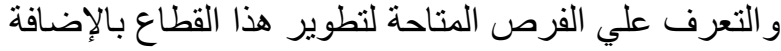

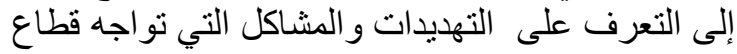
الزينون في محافظة الكرك.

جدول (3): مصفوفة Strengths, Weaknesses, Opportunities, and Threats) SWOT).

\begin{tabular}{|c|c|}
\hline الضعف: 'Weakness & \\
\hline 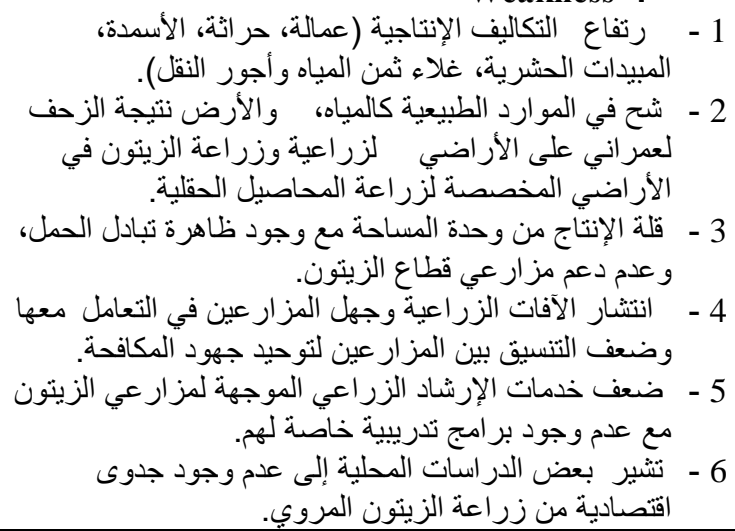 & 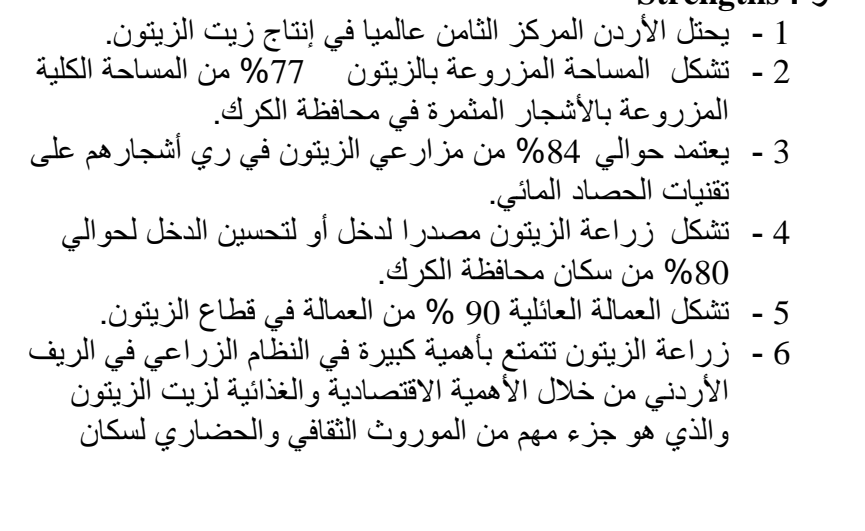 \\
\hline 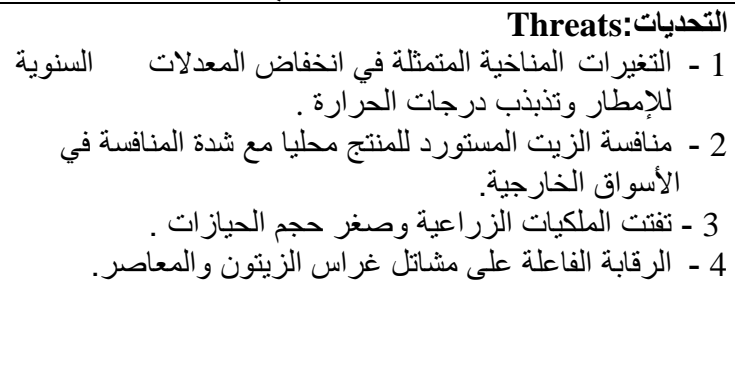 & 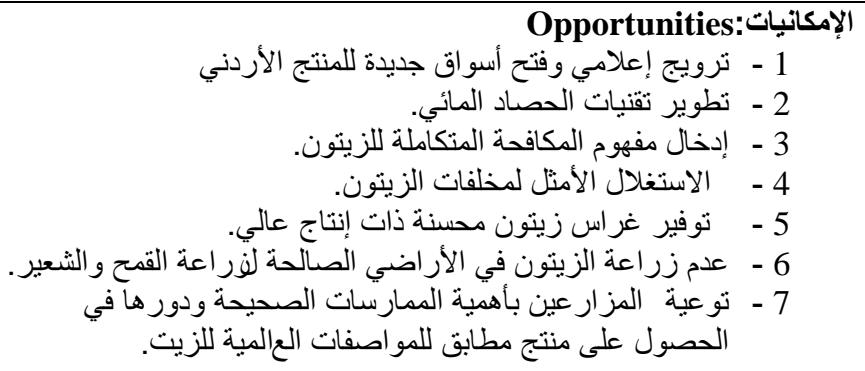 \\
\hline
\end{tabular}

الزيتون وضعف خدمات الإرشاد الزر اعي. إما بالنسبة

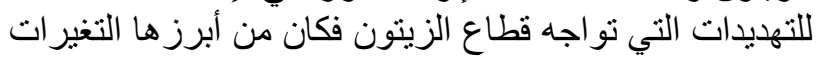

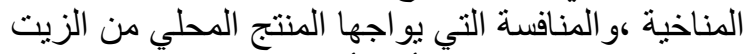

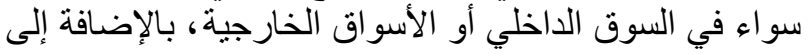

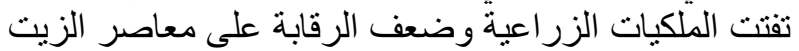

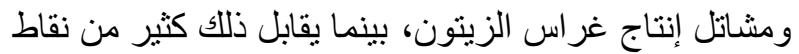

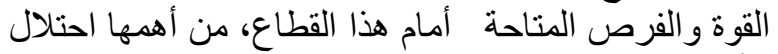

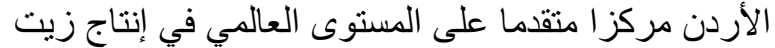

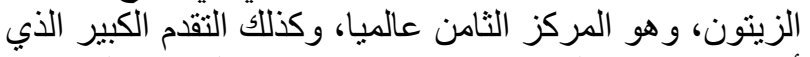

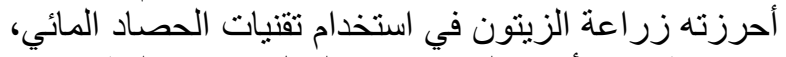
و انخر اط إفر اد أسرة المز ارن فئ في العمل في هذا القطاع مما

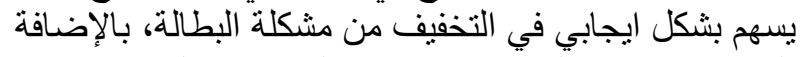

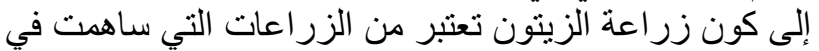
رفع مستوى الدخل للسكان وتحسين نو عية الحئن الحياة في محافظة

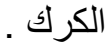

1.5 1.5 التوصيات 1- توصي الدر اسة بوضنع استر اتيجية وطنية شاملة لقطلـاع
5. النتائج والتوصيات

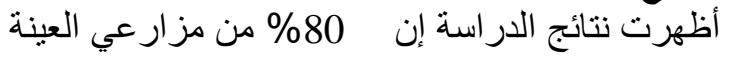

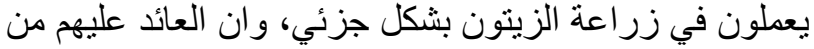

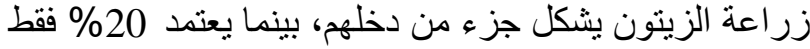

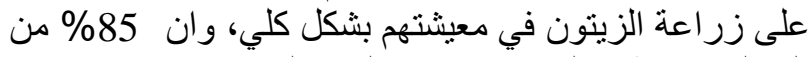

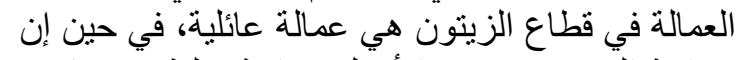

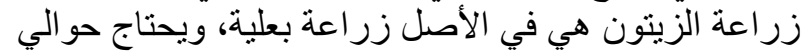

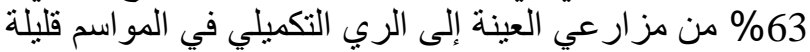

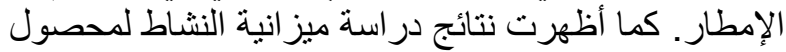

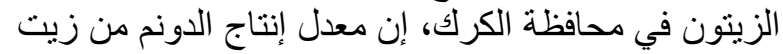

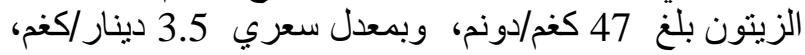

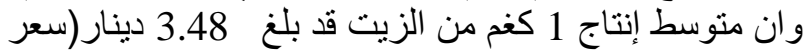

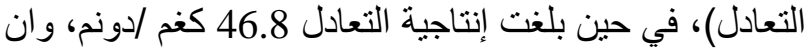
هامش الربح قد بلغ 61.5 دينار /دونم، وصافي العافي العائد (الربح)

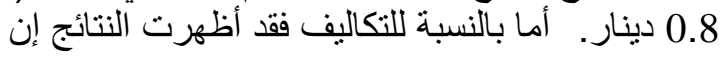

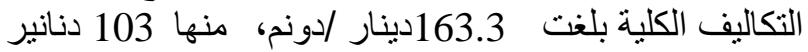

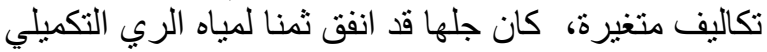
وبنسبة 58\% من التكاليف المتغيرة. 


$$
\begin{aligned}
& \text { المزر عي لمحصول الزيتون في المملكة الأردنية الهاشمية }
\end{aligned}
$$

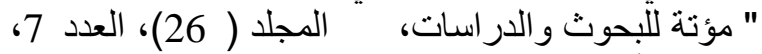

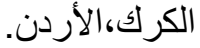

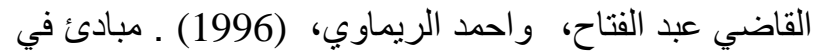

$$
\begin{aligned}
& \text { الإدارة المز رعية، دار حنين للنشر، الإحة عمان ،الأردن. } \\
& \text { دائرة الإحصاءات العامة، الكتاب الإحصائي السنوي، الإني، }
\end{aligned}
$$

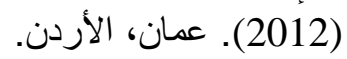

$$
\begin{aligned}
& \text { هندي، محمود، (2009). التحليل الاقتصادي لتكاليف إنتاج }
\end{aligned}
$$

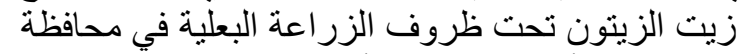

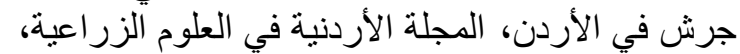

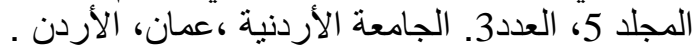

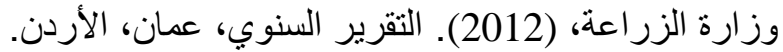

$$
\begin{aligned}
& \text { دائرة الإحصاءات الزراعة العامة، الاحصاءآت الزر اعية، (2012)، } \\
& \text { عمان، الأردن. }
\end{aligned}
$$

Philippe and Vernot J. (2004)"Reclamation's history of the Jordan River basin in Jordan, a focus on agriculture", Ministry of Agriculture, Amman, Jordan.

Stevenson W.J. (1978) Business Statistic, Concepts and Applications, Harper and Row publishers London.
الزيتون، تستعمل نقاط القوة وتستثمر الفرص المتاحة

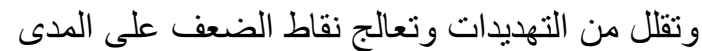

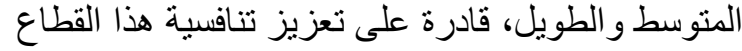

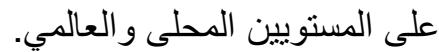

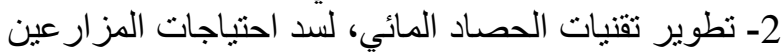

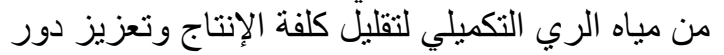

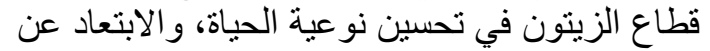
زر اعة الزيتون في المناطق الجافة و التي يقل يقل معدل إمطار ها عن 300ملم الزيتون سنويا.

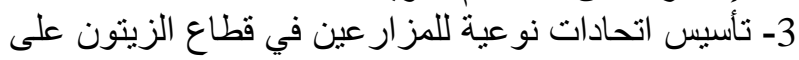

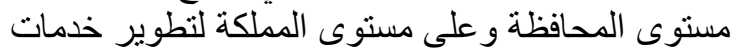

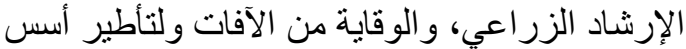

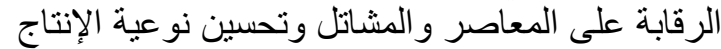
لزيادة الطلب الخارجي على المنتج الأردني من زيت نوعن الريت

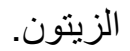

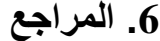

$$
\begin{aligned}
& \text { الجر اح، شوكت رشيد، (2006). اقتصاديات إنتاج الزيتون }
\end{aligned}
$$

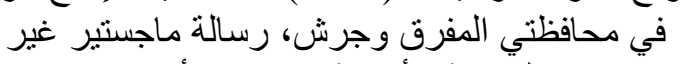

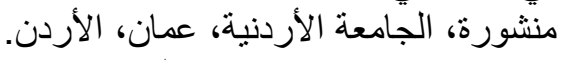

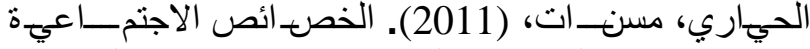

$$
\begin{aligned}
& \text { والاقتصادية لمز ارعي الزيتون ودر اسة ميز انية النشاط الاطي }
\end{aligned}
$$

